\title{
Prevalence of Intermediate Syndrome among Admitted Patients with Organophosphorous Poisoning in a Tertiary Care Hospital
}

\author{
Ananta Bhakta Uprety, ${ }^{1}$ Binod Pantha, ${ }^{1}$ Lochan Karki, ${ }^{1}$ Suresh Prasad Nepal, ${ }^{2}$ Milan Khadka' \\ 'Department of Medicine, Bir Hospital, Kathmandu, Nepal, ${ }^{2}$ Department of General Practice, Bir Hospital, Kathmandu, Nepal.
}

Introduction: Organophosphorous poisoning is a common problem prevalent in Nepal. Intermediate syndrome is a common clinical feature seen among the patients those have ingested poison. There is a scarcity of data related to intermediate syndrome and other general complications in patients with organophosphorous poisoning in context of Nepal. This study was carried out to observe the prevalence of intermediate syndrome and the general complications of oraganophosphorus poisoning among admitted patients in a tertiary care hospital.

Methods: This was a descriptive cross-sectional study conducted at a tertiary care hospital from April 2008 to June 2009 after ethical approval was from Institiutional Review Board of tertiary care hospital. Forty four patients with history of ingestion of organophosphorus poisoning within 24 hours were included in our study through convenience sampling. Clinical examinations were done to look for Intermediate syndrome. Data was entered in Statistical Package for Social Sciences and point estimate at $95 \%$ of CI was calculated along with frequency and proportion for binary data.

Results: Out of 44 patients, features of intermediate syndrome were seen in 40 (90.9\%) at 95\% of $\mathrm{CI}$ (84.2-97.6) patients in the study. The frequency of intermediate syndrome signs like weakness of neck flexion, inability to sit up and swallowing difficulty were seen among the patients. Complications like pneumonia 4 (9.09\%), hyponatremia 3 (6.8\%), hypokalemia $1(2.27 \%)$ and bradycardia $1(2.27 \%)$ were seen in the study. Mortality seen in the study was $2(4.5 \%)$ among the admitted patients.

Conclusions: Prevalence of intermediate syndrome was higher compared to other studies done in similar settings. Complications like pneumonia, hyponatremia, hypokalemia and bradycardia were seen among the patients.

Keywords: gastric lavage; intermediate syndrome; organophophorus poisoning.

\section{INTRODUCTION}

Organophosphorus compounds are used as pesticides, herbicides and chemical warfare agents in the form of nerve gases. Intermediate Syndrome (IMS) develops in 24-96 hours after the ingestion of OP poison, involves the symptoms of weakness of proximal muscle groups, neck, trunk, cranial nerve palsies and decreased tendon reflexes and may require mechanical ventilation. ${ }^{1}$ In our community, poisons consumed are commonly organophosphorous compounds; aluminium phosphide. Gastric lavage is useful within the first four hours of poison ingestion except in tricyclic antidepressants, salicylates and morphine poisoning and in an unconscious patients where lavage can be done several

Correspondence: Dr. Ananta Bhakta Uprety, Department of Medicine, Bir Hospital, Kathmandu, Nepal. Email: uananta2003@ yahoo.com, Phone: +977-9861236050. 
Uprety et al. Prevalence of Intermediate Syndrome among admitted Patients with Organophosphorous Poisoning in a Tertiary Care Hospital

hours later.

In Nepal OP poisoning is very common frequently in the young female population mostly due to domestic violence. No adequate studies are there regarding the complications in the Nepalese context.

The aim of this study is to see the prevalence of intermediate syndrome and other complications associated with Organophosphorus poisoning.

\section{METHODS}

This was a descriptive cross-sectional study conducted at Bir Hospital from April 2008 to June 2009. Ethical approval was taken from Institutional Review committee of Bir hospital. Convenience sampling was done and sample size calculation was calculated using the following formula,

$n=Z^{2} \times(p \times q) / e^{2}$

where,

$\mathrm{n}=$ sample size

$Z=1.65$ for Confidence Interval of $90 \%$

$\mathrm{p}=$ prevalence, $80 \%$ (educated guess)

$q=1-p$

$\mathrm{e}=$ margin of error $=10 \%$

Total sample required for the study was taken to be 44 .

Patients who came to the emergency department with a history of ingestion of OP poison within 24 hours and admitted in the inpatient department were included in the study. Patients with other concomitant poisoning and pregnancy were excluded.

The required information was gathered as per written in the Performa. Informed consent was taken from the patient or from the patient's party. Ingestion of poison was identified by clinical history, tracing the content of the poison (bottle), smell, signs and symptoms. Gastric decontamination by lavage was done until 6 hours from the time of ingestion of poison. The gastric lavage sample was sent to National Forensic Science Laboratory for the determination of the type of poison. Signs and symptoms of OP poisoning were recorded and treatment with atropine and PAM was started to all patients. Clinical examinations were done to look for IMS-like weakness of neck flexion, inability to sit up, ophthalmoparesis, slow eye response, facial weakness, swallowing difficulty, limb weakness (proximal more than distal), areflexia, respiratory insufficiency and each of these symptoms and signs were recorded of patients along with any complications present.

Data was entered in SPSS and point estimate at $95 \%$ of $\mathrm{Cl}$ was calculated along with frequency and proportion for binary data.

\section{RESULTS}

Out of 44 patients, $28(63.6 \%)$ were females and 16 (36.4\%) were males (Figure 1).

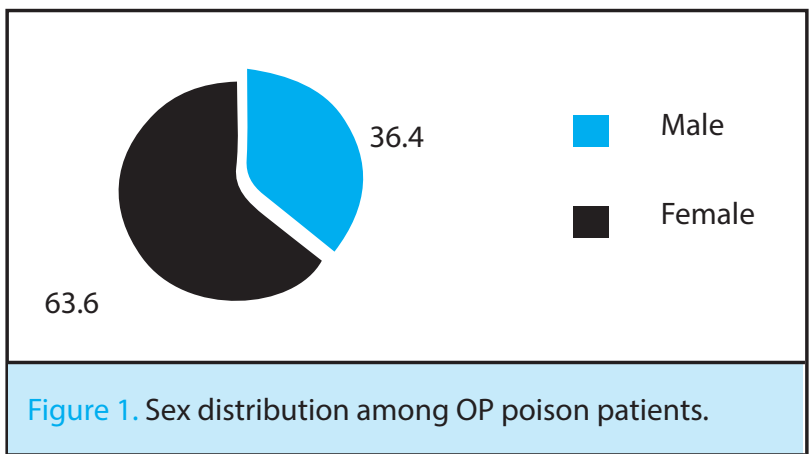

\begin{tabular}{|c|c|c|c|c|}
\hline \multicolumn{2}{|r|}{ Age (in years) } & \multirow{2}{*}{$\begin{array}{l}20-30 \\
9\end{array}$} & \multirow{2}{*}{$\begin{array}{l}31-40 \\
3\end{array}$} & \multirow{2}{*}{$\begin{array}{l}41-50 \\
4\end{array}$} \\
\hline & Male & & & \\
\hline Gender & Female & 18 & 9 & 1 \\
\hline
\end{tabular}

The most frequently observed clinical feature of IMS was weakness of neck flexion among 40 (90\%) followed by inability to sit up in $39(88 \%)$, swallowing difficulty in 34 (77\%), facial weakness in 27 (61\%), limb weakness in 16 (36\%) and opththalmoparesis in 15 (34\%). Slow eye response and areflexia are less observed, however respiratory insufficiency was observed only in 2 patients with IMS (Table 2).

\begin{tabular}{|ll|}
\hline $\begin{array}{l}\text { Table 2. Intermediate syndrome in OP poisoning } \\
\text { patients. }\end{array}$ & $\begin{array}{l}\text { Patients with OP poisoning } \\
\mathrm{n}(\%) \\
\text { Parameters }\end{array}$ \\
$\begin{array}{l}\text { Weakness of neck flexion } \\
\text { Inability to sit up }\end{array}$ & $39(88.6 \%)$ \\
Swallowing difficulty & $34(77.2 \%)$ \\
Facial weakness & $27(61.3 \%)$ \\
Limb weakness (proximal \\
>distal) & $16(36.3 \%)$ \\
Ophthalmoparesis & $15(34.09 \%)$ \\
Slow eye response & $12(27.2 \%)$ \\
Areflexia & $10(22.7 \%)$ \\
Respiratory insufficiency & $2(4.54 \%)$ \\
\hline
\end{tabular}


The most frequent complication was pneumonia accounting for 4 (9.09\%) followed by hyponatremia 3 (6.81\%), hypokalemia $1(2.27 \%)$ and bradycardia 1 (2.27\%) seen among patients (Table 3 ).

\begin{tabular}{|lc|}
\hline $\begin{array}{l}\text { Table 3. Morbidity (complications and hospital stay) } \\
\text { in OP poisoning. }\end{array}$ \\
\hline Complication & Patients with OP poisoning \\
Pneumonia & $4(9.09 \%)$ \\
Hyponatremia & $3(6.81 \%)$ \\
Hypokalemia & $1(2.27 \%)$ \\
Bradycardia & $1(2.27 \%)$ \\
\hline
\end{tabular}

In total, mortality was found among 2 (4.5\%) patients with organophosphorus poisoning.

\section{DISCUSSION}

Organophosphates are widely used in agriculture worldwide and are a common cause of poisoning that continues to result in significant fatalities. This is because of free availability of pesticides and its over-thecounter sale. Certain factors, e.g. severely intoxicated patients, involvement of drugs that delay absorption and gastric emptying (e.g. tricyclic antidepressant), ingestion of substances which require metabolic activation before becoming toxic (e.g. paracetamol, methanol, ethylene glycol, and some organophosphate insecticides), ingestion of large quantities of toxic drugs, absence of bowel sounds on physical examination indicate the possible usefulness of gastric lavage even as long as 4 to 6 hours after ingestion. For the study, as OP poisoning is a potentially lethal situation with relatively high mortality, gastric lavage has been considered up to 6 hours after ingestion.

In our study mean age among both groups of patients with or without gastric lavage was found to be 31 years. Similarly, in a study by Agrawal SB, the maximum number of cases was in the age group of 21 to 30 years. $^{3}$ Another study done by Poojara L, et al. also showed mean age of 30 years among the $\mathrm{OP}$ poisoning cases. The prevalence of OP poisoning in the young age group may be due to the increase in stress because of unemployment, poverty and conflicting relationships in young couples. ${ }^{4}$

Females were found to have higher proportion of poison consumption rate accounting for $63.6 \%$ vs. $36.4 \%$ in males. Male:Female ratio was 1:1.75 in present study. Similar results were found in some other studies, where females were found to have higher of poison consumption rate. ${ }^{2}$

The features of IMS were seen in 40 cases out of 44
(90.9\%) in the present study. The incidence of IMS in different studies has been reported to be between 20$68 \%$. The reported incidence of IMS ranges from $7.7 \%$ to as high as $84 \% .^{5-11}$ In our study, the incidence of IMS was found to be higher compared to other studies. The higher incidence of IMS in our study could be due to the inclusion of patients who had even a single symptom of intermediate IMS e.g. weakness of neck flexion. The late presentation of patients of OP poisoning to the hospital could be the reason for high incidence of IMS in our study.

The most frequent observed clinical features of IMS were weakness of neck flexion, $90.9 \%$ followed by inability to sit up $88.6 \%$, swallowing difficulty $77.2 \%$, facial weakness $61.3 \%$, limb weakness $36 \%$ and opththalmoparesis $34 \%$. Slow eye response and areflexia were less observed, and respiratory insufficiency was observed only in 2 patients with IMS. Clinical features of IMS were observed more among patients who underwent gastric lavage than in patients who didn't. The respiratory insufficiency was observed only in patients with gastric lavage.

In 1987, workers from Sri Lanka described IMS, which included signs of paralysis appearing in $10 \%$ to $40 \%$ of patients that occurred 24 to 96 hours after exposure, i.e. after admission and before the delayed neurotoxicity. ${ }^{12}$

IMS develops 12-96 hrs after exposure and reflects the prolonged action of acetylcholine on the nicotinic receptors. The clinical features are muscular weakness in ocular, neck, bulbar, proximal limb and respiratory muscle with occasional dystonic posturing requiring mechanical ventilation in an ICU for several days. Cranial nerve palsies are common. The risk of mortality is due to the associated respiratory depression. The sensory functions characteristically remain normal and full recovery is evident in 4 to 18 days. It has been commonly associated with organophosphorous compounds like diazinon, dimethoate, methyl parathion, methamidaphe, monocrotophos, fenthion and ethyl parathion. ${ }^{13}$ Despite its common occurrence, data on the risk factors of IMS, early diagnosis and prediction have remained elusive. Commonly used tests such as levels of plasma cholinesterase correlate poorly with the onset of IMS. ${ }^{14}$

Mortality due to IMS was found in 4.5\%. In Sri Lanka, about 10,000 to 20,000 are admitted to hospital for organophosphorus poisoning each year. Among cases, at least $10 \%$ died. ${ }^{15}$ Case mortality across the developing world is commonly greater than $20 \% .^{16}$ The study conducted in Multan from 1996 to 2000 showed 370 patients of OP poisoning with a mortality rate of $15 \%$. Although, complications were seen more frequently in the gastric lavage group, early lavage was associated with lower mortality rate. 
In present study, complications occurred more common among patients with gastric lavage, and the most frequent complication was pneumonia accounting $11.5 \%$ followed by hyponatremia, hypokalemia, bradycardia at the time of discharge, 3.8\% in each among patients with gastric lavage. However, hyponatremia was most frequent complication occurred among patients without gastric lavage accounting $11.1 \%$ followed by pneumonia i.e. $5.5 \%$ and no cases of hypokalemia and bradycardia observed in the said group.

Pneumonia was observed among the patients with little higher level of serum cholinesterase level (1000 U/L to 1700 U/L). Hyponatremia, hypokalemia and bradycardia at the time of discharge were found among the patients with low level of serum cholinesterase level (200 U/L to1000 U/L). Similar types of complications were found in many studies. A study from Pakistan by Saleem Faiz, et al. mentioned about the acute complications like fits in $16.66 \%$, bradycardia in $10 \%$ and hyperglycemia in $5 \%$ patients. ${ }^{17}$ Acute complications similar to this study were episodic convulsions developed in $16.66 \%$ patients, while $6.66 \%$ patients developed profuse diarrhea, and severe bradycardia was seen in $10 \%$ patients, hypotension in $10 \%$ patients, whereas $5 \%$ patients developed hyperglycemia and $1.66 \%$ patients developed acute renal failure in a study from Kashmir, India. ${ }^{18}$ Acute complications included hypokalemia in

\section{REFERENCES}

1. Senanayake N, Karalliedde, L. Neurotoxic effects of organophosphorus insecticides. An intermediate syndrome.

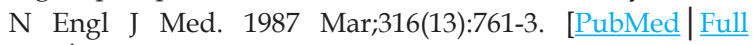
Text|DOI]

2. Karalliedde L, Senanayake N. Acute organophosphorous insecticides poisoning in Sri Lanka. Forensixc Sci Int. 1988 Jan;36(1-2):97-100. [PubMed | Full Text | DOI]

3. Agrawal SB. A clinical biochemical, neurobehavioral and sociopsychological study of 190 patients admitted to hospital as result of acute organophosphorous poisoning. Environ Res. 1993 Jul;62(1):63-70. [PubMed | Full Text | DOI]

4. Poojara L, Vasudevan D, Arun Kumar A, Kamat V. Organophosphate poisoning: Diagnosis of intermediate syndrome. Indian J Crit Care Med. 2003;7(2):94-102. [Full Text]

5. De Bleecker J, Van Den Neucker K, Colardyn F. Intermediate syndrome in organophosphorus poisoning: a prospective study. Crit Care Med. 1993;21(11):1706-11. [

6. He F, Xu H, Qin F, Xu L, Huang J, He X. Intermediate myasthenia syndrome following acute organophosphates poisoning:an analysis of 21 cases. Hum Exp Toxicol. 1998

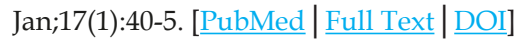

7. Lee P, Tai DYH. Clinical features of patients with acute
$40.9 \%$, respiratory failure in $23.5 \%$, hyponatremia in $23.5 \%$, non-cardiogenic pulmonary edema in $18.26 \%$, acute kidney injury in $11.3 \%$, hypernatremia in $9.6 \%$, mixed acidosis in $6.1 \%$, metabolic acidosis in $5.2 \%$ and respiratory acidosis in $2.6 \%$.

These were found in study done in Nepal which support our results regarding the complications of OP poisoning. ${ }^{19}$ Limitation of this study is small sample size due to which result could have been exaggerated or less accurate. Also, long term follow-up of the patients were not there so that remote complications were not observed.

\section{CONCLUSIONS}

Prevalence of Intermediate Syndrome was higher compared to other studies. Clinical signs of IMS were seen in most of the cases where it occurred from day 2 to day 5. Complications like pneumonia, hyponatremia, hypokalemia, and bradycardia were more prevalent among the group of patients who underwent gastric lavage.

Conflict of Interest: None.

organophosphate poisoning requiring intensive care. Intensive Care Med. 2001;27(4):694-9. [ [ Text|DOI]

8. Khan S, Hemalatha R, Jeyaseelan L, Oommen A, Zachariah A. Neuroparalysis and oxime efficacy in organophosphate poisoning:a study of butyryl-cholinesterase. Hum Exp Toxicol. 2001;20(4):169-74. [PubMed | Full Text | DOI]

9. John M, Oommen A, Zachariah A. Muscle injury in organophosphorus poisoning and its role in the development of intermediate syndrome. Neurotoxicology. 2003;24(1):43-53. [PubMed | Full Text]

10. Dandapani M, Zachariah A, Kavitha MR, Jeyaseelan L, Oommen A. Oxidative damage in intermediate syndrome of acute organophosphorus poisoning. Ind J Med Res. 2003;117:253-9. [PubMed]

11. Guven M, Sungur M, Eser B, Sari I, Altuntas F. The effects of fresh frozen plasma on cholinesterase levels and outcomes in patients with organophosphate poisoning. J Toxicol Clin Toxicol. 2004;42(5):617-23. [․ pubMed]

12. De Bleeker J, Van Den Neucker K, William J. Intermediate syndrome in organophosphorous poisoning: presentation of a case and review of literature. J Toxicol Clin Toxicol. 1992;30(3):321-9. [PubMed | DOI]

13. Pali S, Jayakumar J, Dham SK. Intermediate syndrome in organophosphorous poisoning-A case report. Kathmandu Univ Med J (KUMJ). 2005;3(12):421-2. [Full Text] 
14. Singh S, Sharma N. Neurological syndromes following organophosphate poisoning. Neurol India. 2000;48(4):308-13. [PubMed | Full Text]

15. Ayugun D, Doganay, Altintop L, Guven H, Onar M, Deniz $\mathrm{T}$, et al. Serum acetylcholinesterase and prognosis of acute organophosphate poisoning. J Toxicol Clin Toxicol. 2003;4(7):903-10. [PubMed]

16. Eddelston M, Singh S, Buckley N. Organophosphorus poisoning (acute). BMJ Clin evid. 2007;2007:2102. [Full Text]
17. Faiz MS, Mughal S, Memon AQ. Acute and Late Complications of Organophosphate Poisoning. J Coll Physicians Surg Pak. 2011;21(5):288-90. [Full Text]

18. Malik GM, Mubarik M, Romshoo GJ. Organophosphorus poisoning in the Kashmir Valley, 1994-1997. N Engl J Med. 1998 Apr;338(15):1078. [uuMed | Full Text | DOI]

19. Laudari S, Patowary BS, Sharma SK, Dhungel S, Subedi K, Bhattacharya R, et al. Cardiovascular effects of acute Organophosphate poisoning. Asia Pac J Med Toxicol. 2014 Jun;3(2):64-7. [Full Text] 